\title{
KHẢO SÁT SƯ TíCH LŨY Pb TỪ MÔI TRƯờNG TỰ NHIÊN LÊN CÁ Rô PHI VÀ ĐÁNH GIÁ RỦI RO SỨC KHỎE ĐỐI VớI NGƯờI SỬ DỤNG
}

\author{
Nguyễn Minh Trí *, Trần Thị Như Xuân, Nguyễn Hải Phong \\ Truò̀ng Đại học Khoa học, Đại học Huế \\ (Ngày đến tòa soạn: 30/6/2019; Ngày sưa bài sau phản biện: 11/9/2019; \\ Ngày chấp nhận đăng: 20/9/2019)
}

\section{Tóm tắt}

Cá Rô phi là món ăn rất phổ biến trong bữa cơm hàng ngày của nhiều gia đình ở Việt Nam hiện nay, tuy nhiên những nghiên cứu về mức độ tích lũy kim loại chì $(\mathrm{Pb})$ trong cơ thể của loài cá này vẫn chưa được quan tâm một cách cụ thể. Kết quả nghiên cứu cho thấy: cá Rô phi vằn được khảo sát ở một số hồ thuộc kinh thành Huế có hàm lượng $\mathrm{Pb}$ trong phần thịt ở mức cao so với tiêu chuẩn cho phép của Bộ Y tế nên không đảm bảo an toàn cho người sử dụng. Hệ số tích lũy sinh học BSAF của $\mathrm{Pb}$ ở mức thấp và có mối tương quan chặt về hàm lượng $\mathrm{Pb}$ trong trầm tích với $\mathrm{Pb}$ trong phần thịt của cá. Chỉ số rủi ro sức khỏe ở phần cơ của loài này đối với $\mathrm{Pb}$ là ở mức cao nên khi sử dụng cá khai thác từ các khu vực này sẽ ảnh hưởng xấu cho sức khỏe người sử dụng.

Tù khóa: Cá rô phi, $P b$, tích lũy sinh học, rủi ro sức khỏe.

\section{1. ĐẶT VẤN ĐỀ}

Trong những năm gần đây, ô nhiễm kim loại nặng do các hoạt động của con người gây ra có xu hướng gia tăng trong môi trường. Kim loại nặng có khả năng tích tụ và rất khó phân hủy, gây ngộ độc tức thời hay ảnh hưởng lâu dài đến sức khỏe con người và đời sống sinh vật. Việc xả thải các chất thải công nghiệp và sinh hoạt chưa qua xử lý vào các sông hồ đã làm cho chất lượng nước và bùn đáy bị suy giảm nghiêm trọng. Hàm lượng cao của các kim loại nặng được tích tụ trong nước và bùn đáy sẽ gây ảnh hưởng đến sự phát triển của các loài sinh vật thủy sinh. Các kim loại này sẽ được tích tụ trong các mô của sinh vật thủy sinh và hơn nữa có thể gây ảnh hưởng đến sức khỏe con người thông qua chuỗi thức ăn.

Cá Rô phi vằn (Oreochromis niloticus) được nhập vào nước ta từ năm 1951, hiện nay đã sinh sống rộng khắp tại các sông suối, kênh rạch, ao hồ... trên cả nước nói chung và ở tỉnh Thừa Thiên Huế nói riêng. Đây là loài ăn tạp, chúng sử dụng hầu hết các loại thức ăn tự nhiên, mùn bã hữu cơ, ấu trùng, côn trùng, thực vật thuỷ sinh... Hiện nay cá Rô phi là món ăn rất phổ biến trong bữa cơm hàng ngày của nhiều gia đình ở Việt Nam, tuy nhiên những nghiên cứu về mức độ tích lũy các kim loại nặng trong cơ thể của loài cá này vẫn chưa được quan tâm một cách cụ thể. Bài báo này giới thiệu một số kết quả về hàm lượng $\mathrm{Pb}$ tích tụ trong cơ thể cá Rô phi và đánh giá nguy cơ rủi ro sức khỏe đối với con người của kim loại này để có thể cung cấp những thông tin về an toàn thực phẩm cho người sử dụng.

\section{2. ĐỐI TƯợNG VÀ PHƯƠNG PHÁP NGHIÊN CÚU}

Loài cá rô phi vằn: Oreochromis niloticus (Linnaeus, 1758) sống ở khu vực các hồ Tịnh Tâm (địa điểm 1), Xã Tắc (địa điểm 2) và hồ Tự (địa điểm 3) thuộc thành phố Huế. Mẫu trầm tích được thu bằng cuốc bùn chuyên dụng, các loại mẫu được thu trong 2 đợt vào tháng 11/2018 (đợt 1) và 
tháng 4/2019 (đợt 2). Mẫu thu được bảo quản ở nhiệt độ từ $4-10^{\circ} \mathrm{C}$.

Mẫu cá có khối lượng trung bình từ 200 - $350 \mathrm{~g} / \mathrm{con}$ được tách lấy phần cơ (thịt cá) và sấy ở nhiệt độ từ $70-105^{\circ} \mathrm{C}$ cho đến khô hoàn toàn. Mẫu trầm tích được loại bỏ các tạp chất, hong khô trong không khí ở nhiệt độ phòng. Các loại mẫu được nghiền nhỏ bằng máy nghiền đồng thể và bảo quản trong bình hút ẩm.

Vô cơ hóa mẫu theo TCVN 7602:2007 [7], pha loãng dung dịch vô cơ này bằng nước cất 2 lần để phân tích kim loại $\mathrm{Pb}$ bằng phương pháp quang phổ hấp thụ nguyên tử AAS (Atomic Absorption Spectrometers) trên máy Analyst 800 của hãng Perkin Elmer - USA.

Xác định hệ số tích lũy sinh học BSAF (Biota-sendiment accumulation factor) [10] theo công thức:

$$
\mathrm{BSAF}=\frac{\text { Hàm lượng kim loại trong mẫu cá }(\mathrm{mg} / \mathrm{kg})}{\text { Hàm lượng kim loại trong trầm tích }(\mathrm{mg} / \mathrm{kg})}
$$

Xác định hệ số rủi ro sức khỏe RQ (risk quotient) theo công thức:

$$
\mathrm{RQ}=\frac{\text { Hàm lượng kim loại trong mẫu }(\mathrm{mg} / \mathrm{kg})}{\text { Giới hạn hàm lượng kim loại theo QCVN 8-2:2011/BYT }(\mathrm{mg} / \mathrm{kg})}
$$

Mức độ rủi ro sức khỏe đối với con người được đánh giá như sau:

$$
\begin{array}{ll}
\mathrm{RQ}: 0,01-0,1 \text { : rủi ro thấp } & \mathrm{RQ}: 0,1-1 \text { : rủi ro trung bình } \\
\mathrm{RQ}>1 \text { : rủi ro cao } & \mathrm{RQ}>100 \text { : rủi ro rất cao [8]. }
\end{array}
$$

Các số liệu được xử lý theo phương pháp thống kê, so sánh các giá trị trung bình theo phân tích Anova với mức ý nghĩa $\alpha=0,05$ bằng chương trình Microsoft Excel [6].

\section{KẾT QUẢ VÀ BÀN LUẬN}

Sự tích lũy kim loại trong các đối tượng thủy sản chịu sự ảnh hưởng của các yếu tố thức ăn và môi trường sống. Chính vì vậy, để có cơ sở đánh giá nguồn ô nhiễm và sự tích lũy kim loại nặng trong cá Rô phi, chúng tôi đã tiến hành phân tích hàm lượng kim loại $\mathrm{Pb}$ trong trầm tích và cơ thể cá.

\subsection{Hàm lượng $\mathrm{Pb}$ trong trầm tích}

Hầu hết các kim loại nặng thường khó phân hủy trong môi trường và chúng tồn tại ở tầng sâu như nước tầng đáy và trầm tích ở sông, hồ,... nên nguy cơ nhiễm kim loại vào các đối tượng thủy sản là rất cao, qua đó sẽ dẫn đến tích lũy sinh học và ảnh hưởng đến sức khỏe người sử dụng thông qua chuỗi thức ăn. Kết quả khảo sát về hàm lượng $\mathrm{Pb}$ trong trầm tích của các hồ được thể hiện ở hình 1 .

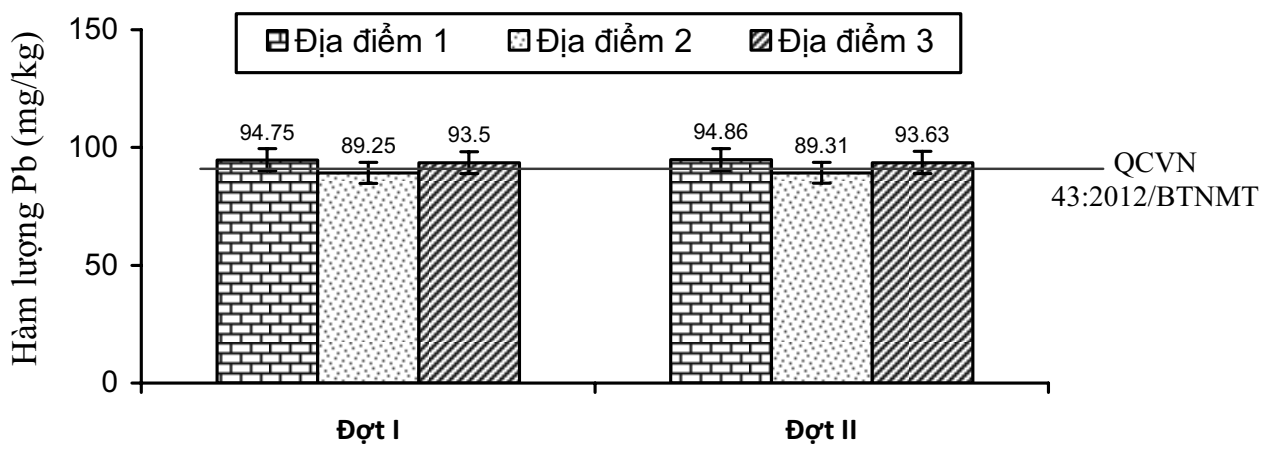

Hình 1. Hàm lượng kim loại Pb trong trầm tích ở các hồ được khảo sát

Kết quả ở hình 1 cho thấy kim loại $\mathrm{Pb}$ có tồn tại trong trầm tích của các hồ, tuy nhiên trầm tích ở hồ Tịnh Tâm (địa điểm 1), Xã Tắc (địa điểm 2) được khảo sát có hàm lượng $\mathrm{Pb}$ đều vượt giới hạn 
cho phép theo QCVN 43:2012/BTNMT qui định là 91,3 mg/kg [2]. Giá trị trung bình về hàm lượng $\mathrm{Pb}$ trong trầm tích của 2 đợt lấy mẫu ở các địa điểm khảo sát có sự biến động, nhưng sai khác không có ý nghĩa thống kê $(\mathrm{P}>0,05)$ giữa các đợt thu mẫu.

So với kết quả phân tích về hàm lượng $\mathrm{Pb}$ trong trầm tích ở một số sông hồ của các tác giả khác cho thấy hàm lượng $\mathrm{Pb}$ ở khu vực khảo sát của chúng tôi cao hơn trong trầm tích ở trại nuôi trồng thủy sản thuộc Học viện Nông nghiệp Việt Nam dao động từ 29,94 - 33,50 mg/kg [1], cũng như kết quả phân tích hàm lượng $\mathrm{Pb}$ trong trầm tích ở sông Nhuệ và sông Đáy của Vũ Đức Lợi $(26,14-89,77 \mathrm{mg} / \mathrm{kg})$ [5]. Theo chúng tôi, các hồ được khảo sát ở thành phố Huế đã tiếp nhận một lượng lớn nước thải sinh hoạt của các hộ gia đình xung quanh chưa qua xử lý và hơn nữa các hồ này không có sự lưu thông nước, do vậy sẽ tích tụ một lượng lớn kim loại $\mathrm{Pb}$ trong nền đáy hồ theo thời gian.

\subsection{Hàm lượng $\mathrm{Pb}$ trong cơ thể cá}

Để có cơ sở đánh giá mức độ ô nhiễm kim loại nặng, sự tích lũy và mối tương quan giữa hàm lượng $\mathrm{Pb}$ trong môi trường và động vật thủy sản, chúng tôi đã tiến hành lấy mẫu và phân tích hàm lượng $\mathrm{Pb}$ trong phần thịt cá Rô phi, kết quả được thể hiện ở hình 2.

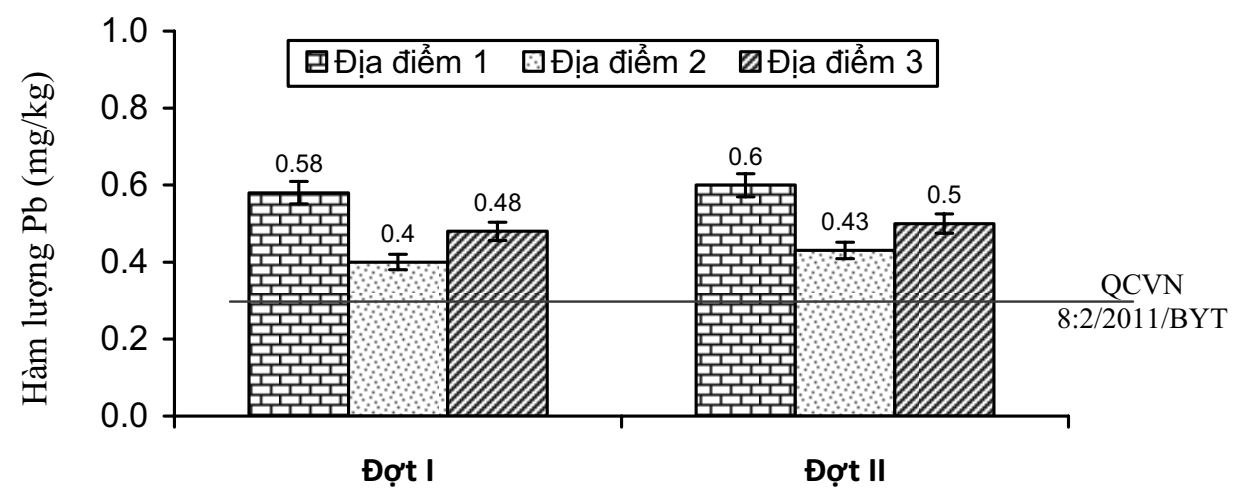

Hình 2. Hàm lượng Pb trong thịt của cá Rô phi ở các địa điểm khảo sát

Theo kết quả được trình bày ở hình 2 cho thấy hàm lượng Pb trung bình trong cơ (thịt) cá tăng dần qua hai đợt tại các địa điểm được khảo sát. Cụ thể ở đợt 1 , hàm lượng $\mathrm{Pb}$ dao động từ 0,40 $0,58 \mathrm{mg} / \mathrm{kg}$ và có tăng vào đợt $2: 0,43-0,6 \mathrm{mg} / \mathrm{kg}$; nhìn chung sự biến động này không có ý nghĩa thống kê giữa 2 đợt thu mẫu khảo sát. So sánh với tiêu chuẩn về hàm lượng Pb theo QCVN 8-2/2011BYT [3] là $0,3 \mathrm{mg} / \mathrm{kg}$, thì kết quả này cho thấy hàm lượng $\mathrm{Pb}$ trong thịt cá ở các địa điểm khảo sát đều vượt giới hạn cho phép dùng làm thực phẩm, cho thấy đây là vấn đề cần quan tâm.

So sánh kết quả nghiên cứu này với kết quả phân tích kim loại trong cá chép nuôi tại trại nuôi trồng thủy sản của Học viện Nông nghiệp Việt Nam (2015) cho thấy hàm lượng $\mathrm{Pb}$ trong thịt cá Rô phi dao động từ $(0,40-0,60 \mathrm{mg} / \mathrm{kg})$ và cao hơn trong thịt của cá chép $(0,05-0,09 \mathrm{mg} / \mathrm{kg})[1]$. Theo Olsson (1998) về cơ chế tích lũy kim loại: con đường hấp thu kim loại chủ yếu của cá là từ mang và thức ăn vào ruột, trong quá trình lưu thông máu và trao đổi chất nó sẽ được vận chuyển đến các bộ phận khác trong cơ thể, đặc biệt là cơ [9]. Kết quả khảo sát về sự tích lũy $\mathrm{Pb}$ có trong môi trường đã ảnh hưởng đến cơ thể cá và người tiêu dùng cần có giải pháp xử lý hoặc hạn chế sử dụng cá Rô phi sống ở địa điểm này.

\section{3. Đánh giá mức độ tích lũy $\mathbf{P b}$ của cá rô phi}

Hệ số tích lũy sinh học (BSAF) thể hiện mối tương quan giữa hàm lượng kim loại trong các bộ phận của cá và hàm lượng kim loại trong trầm tích ở khu vực cá sinh sống. Kết quả nghiên cứu cho 
thấy hệ số BSAF của $\mathrm{Pb}$ biến động qua các đợt đối với các bộ phận khác nhau của cá Rô phi là không giống nhau (hình 3).

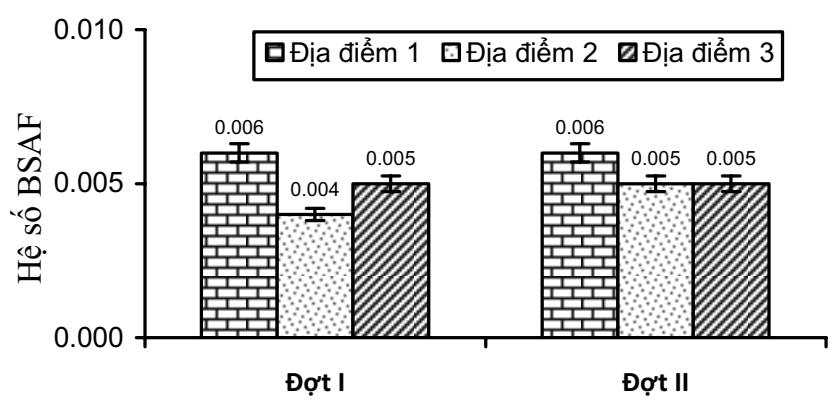

Hinh 3. Hệ số tích lũy kim loại (BSAF) trong trầm tích đối với phần cơ của cá

Hệ số BSAF của $\mathrm{Pb}$ đối với các địa điểm khảo sát đều rất thấp, theo chúng tôi nguyên nhân có thể là do hàm lượng $\mathrm{Pb}$ trong phần thịt của cá thấp hơn nhiều so với mẫu trầm tích của hai đợt thu mẫu khảo sát. Kết quả xác định về tương quan giữa hàm lượng kim loại trong trầm tích và tích tụ trong phần cơ (thịt cá) đối với $\mathrm{Pb}$ là $\mathrm{r}=0,99$ cho thấy có mối tương quan rất chặt chẽ. Từ đây có thể bước đầu nhận định là hàm lượng $\mathrm{Pb}$ trong thịt cá hiện tại chịu ảnh hưởng bởi hàm lượng $\mathrm{Pb}$ có trong trầm tích. Điều này có thể là do tập tính sinh sống của cá với thức ăn chính là mùn bã hữu cơ và động thực vật nên cần có thời gian và những nghiên cứu chuyên sâu hơn nữa để đánh giá về sự tích lũy $\mathrm{Pb}$ trong cá bởi các nguồn thức ăn.

\section{4. Đánh giá rủi ro sức khỏe}

Đánh giá rủi ro sức khỏe là đánh giá các mối nguy hại tiềm tàng ảnh hưởng đến sức khỏe khi con người phơi nhiễm với các chất độc hại [4]. Để đánh giá mức độ rủi ro của $\mathrm{Pb}$ đến sức khỏe người sử dụng, chúng tôi sử dụng chỉ số RQ (risk quotient), kết quả tính toán chỉ số RQ được thể hiện ở bảng 1 .

Bảng 1. Chỉ số rủi ro súc khỏe (RQ) đối với người sử dụng

\begin{tabular}{|l|c|c|c|}
\hline & Địa điểm 1 & Địa điểm 2 & Địa điểm 3 \\
\hline Đợt 1 & 1,917 & 1,333 & 1,583 \\
\hline Đợt 2 & 2,000 & 1,417 & 1,667 \\
\hline
\end{tabular}

Kết quả ở bảng 1 cho thấy hầu hết các mẫu cá được khảo sát đều có mức rủi ro cao $(\mathrm{RQ}>1)$. Do vậy, cần tăng cường công tác giám sát và tìm cách hạn chế mức độ rủi ro đối với sức khỏe con người bằng các biện pháp tuyên truyền, nâng cao ý thức trong người dân về an toàn thực phẩm.

\section{KẾT LUẬN}

Cá Rô phi vằn (Oreochromis niloticus) được khảo sát ở hồ Tịnh Tâm, hồ Xã Tắc và hồ Tự thuộc kinh thành Huế có hàm lượng $\mathrm{Pb}$ trong phần thịt ở mức cao và không đạt tiêu chuẩn cho phép của Bộ Y tế về an toàn thực phẩm cho người sử dụng.

Hệ số tích lũy sinh học $\mathrm{BSAF}$ về kim loại $\mathrm{Pb}$ của loài này ở mức thấp và có mối tương quan chặt giữa hàm lượng kim loại trong trầm tích với kim loại trong phần thịt của cá.

Chỉ số rủi ro sức khỏe của $\mathrm{Pb}$ đối với cá Rô phi được khảo sát là ở mức cao nên khi sử dụng cá khai thác từ các khu vực này sẽ ảnh hưởng xấu cho sức khỏe người sử dụng. 


\title{
TÀI LIẸU THAM KHẢO
}

1. Phạm Kim Đăng, Bùi Thị Bích và Vũ Đức Lợi (2015), "Nghiên cứu về sự tích lũy kim loại nặng trong cá Chép nuôi tại trại nuôi trồng thủy sản”, Tạp chí khoa học và phát triển (2015), tập 13 số 3, tr: 394-400.

2. Bộ Tài nguyên - Môi trường (2012). QCVN 43:2012/BTNMT. Quy chuẩn kỹ thuật quốc gia về chất lượng trầm tích.

3. Bộ Y tế (2011). QCVN 8-2:2011/BYT. Quy chuẩn kỹ thuật quốc gia đối với giới hạn ô nhiễm kim loại nặng trong thực phẩm.

4. Lâm Quốc Hùng, Trần Quang Trung, Nguyễn Hùng Long, Hà Thu Huyền (2012), "Một số kết quả ban đầu trong điều tra tổng lượng ăn vào đối với một số kim loại nặng trong thực phẩm tại địa bàn thành phố Hà Nội năm 2011”, Tạp chí Y học Thực hành, số 482.

5. Vũ Đức Lợi, Nguyễn Thanh Nga, Trịnh Anh Đức, Phạm Gia Môn, Trịnh Hồng Quân, Dương Tuấn Hưng, Trần Thị Lệ Chi và Dương Thị Tú Anh (2010), "Phân tích một số kim loại nặng trong bùn thuộc lưu vực sông Nhuệ và Đáy”, Tạp chí phân tích Hóa, Lý và Sinh học, 15: 26.

6. Chu Văn Mẫn (2001), "Ứng dụng tin học trong sinh học”, NXB Đại học quốc gia Hà Nội.

7. TCVN 7602:2007. Thực phẩm - Xác định hàm lượng chì bằng phương pháp quang phổ hấp thụ nguyên tử.

8. Lê Thị Hồng Trân (2008), “Đánh giá rủi ro môi trường”, NXB Khoa học Kỹ thuật.

9. Olsson Per-Erik, Peter Kling, Christer Hogstrand (1998), "Mechanisms of heavy metal accumulation and toxicity in fish", Metal Metabolism in Aquatic Environments, p. 321- 350.

10. Lawrence Burkhard (2009). Estimation of biota sediment accumulation factor (BSAF) from paired observations of chemical concentrations in biota and sediment. US. Environmental Protection Agency.

\section{Summary}

\section{LEAD ACCUMULATION IN FISH OREOCHROMIS NILOTICUS AND HUMAN HEALTH RISK ASSESSMENT FOR CONSUMERS}

\author{
Nguyen Minh Tri, Tran Thi Nhu Xuan, Nguyen Hai Phong \\ University of Science, Hue University
}

Tilapia (Oreochromis niloticus) is very popular in the daily meals of many families in Vietnam. However, lead accumulation in this type of fish has not been taken specifically. Results showed that the nile tilapia in several lakes in the Hue city contented high levels of Pb content exceeding the permitted levels issued by the Ministry of Health. Therefore, consuming them may not be safe. The BSAF bioaccumulative coefficient of Pb was low and there was a strong correlation between $\mathrm{Pb}$ contents in sediment and in the flesh of the fish. The risk quotient (RQ) higher than 1 indicated that consuming fish exploited from these areas may endanger users' health.

Keyword: Oreochromis niloticus, lead, human health risk. 